\title{
The Relationship Between The Manager's Managerial Practice And The Location Of Automotive Service Business
}

\author{
Jeen-fong Li, (E-mai:shuhor@hotmail.com), National Taiwan Normal University, Taiwan
}

\begin{abstract}
The gap between the development of rural and urban areas is widening in Taiwan. The population of metropolitan areas keeps growing while that of rural areas stagnates. Certain rural towns even experienced negative growth. Transportation and industrial development in the eastern and the western parts of this island is also quite unbalanced. Aside from environmental factors, the shortage of managers' knowledge of total quality management (TQM) is the primary barrier to applying TQM in an enterprise. Based on the background, this research was focused on the relationship between the managers' managerial practice (MP) and the locations of the automotive service businesses. Consequently, it was found that the managers who work in the eastern areas of Taiwan are better than those who work the other regions in terms of $M P$.
\end{abstract}

\section{RESEARCH MOTIVATION}

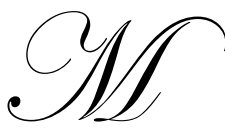

ost enterprises implemented TQM in their institutes during the late 1990's (Chao, 1999; Davis \& Lea, 1995). That means that TQM has made a contribution to these enterprises. However, how important it is to these enterprises? TQM still has some limitations, especially in a multi-cultural society (Sohal, 1997; Williams \& Johnson, 2004). That is why nowadays there are a few small and medium size businesses that have not be implemented TQM. Automotive service businesses belong to the small business sector in Taiwan. Would TQM suit their needs? According to Ehresman's study, TQM can be implemented in small businesses as effectively as in big enterprises (Ehresman, 1995). Therefore, it is worth studying whether to implement TQM in automotive service businesses or not.

\section{RESEARCH PURPOSES}

The purposes of this study were to find the relationships between a manager's managerial practice and the location of an automotive service business. So, the two main purposes of the study are as follows:

1. To investigate the managerial practice of automotive service businesses;

2. To test whether the managerial practice of automotive service businesses would be affected by the locations of automotive service businesses.

There is only one research hypothesis in this study: there is no significant correlation between the managerial practice and the location of an automotive service business.

\section{LITERATURE REVIEWS}

Simply speaking, management is how to make other people to achieve the organizational goals by planning, structuring, directing, comprising, and controlling which means the people is the main core of the management system. Of course, there are many other scholars defining its nature by standing different positions 
(Robbins et al., 2005). If the management is put as a business, it can make its products and earn its profit. In other words, the management can create its benefit. Since it can produce its products, it should have its resources. The resources refer to the sources of the data that can be used to rework into a product and can be flexibly applied to any kinds of products (Brown \& Duguid, 2000).

There are two main kinds of resources in the earth: natural resources and human affairs. We can subdivide the natural resources into two kinds of resources. One is natural sources such as oil, coal, forest, plants, and mineral; the other is artificial sources such as woods, silk, cotton, iron, and steel materials. Human affairs are the sources of human being which are formed by them those are living in their life and the way they are doing every thing individuals, then putting their behaviors together to produce a result of the human culture that puts back to affect human's behaviors. Therefore, it will get the different results how to use the human's culture or what degree of developing the human's culture in an organization (Fisher \& White, 2000; Gupta \& Govindaraljan, 2002; Eddleston et al., 2002; Gutek, et al., 2002).

Total quality management infuses quality values throughout every activity within an organization, with forefront workers intimately involved in the process, then delivering quality to customers in order to increase the competition abilities of an organization in the global market (Samson \& Daft, 2003). Generally, there are four main elements of total quality management: benchmarking, continuous improvement, employee involvement and focus on the customer (Greengard, 1997). Benchmarking is a procedure that involves finding out how other companies do something better, and then trying to improve and/or match on their performance (Hof \& Hamm, 2002). Continuous improvement is doing small, incremental improvements in all areas of the organization on an ongoing basis (Kesner, 2002). Employee involvement requires organization-wide partaking in quality control (Gale, et al., 2002). Focus on customers means that firstly to find out what customers want and try to meet their needs and expectations, then to require all employees to focus on the customer (Eddleston, et al., 2002; Pugh, et al., 2002)..

Taiwan is a society with a free-market economy which is ranked the first or second in the world in terms of foreign currency reserves in 1994 and seventh as a source of the investment capital in 2002. According to the World Bank, Taiwan was also the $18^{\text {th }}$ largest among trading nations worldwide. In addition, it is ranked $34^{\text {th }}$ in terms of GNP and $35^{\text {th }}$ in terms of per capital income in the world (Lin, 2004).

\begin{tabular}{|c|c|c|c|c|}
\hline & GDP (\%): & $5.86 / 2000$ & $-2.18 / 2001$ & $3.59 / 2002$ \\
\hline & GNP (US\$ billion): & $313.9 / 2000$ & $286.8 / 2001$ & $289.3 / 2002$ \\
\hline - & Per Capita GNP (US\$): & $14,188 / 2000$ & $12,876 / 2001$ & $12,916 / 2002$ \\
\hline & Annual Economic Growth Rate(\%): & $1.26 / 2000$ & $-0.01 / 2001$ & $-0.20 / 2002$ \\
\hline & Unemployment Rate $(\%)$ : & $3.00 / 2000$ & $4.60 / 2001$ & $5.17 / 2002$ \\
\hline & Foreign Trade (US\$ billion): & $106.7 / 2000$ & $122.2 / 2001$ & $161.7 / 2002$ \\
\hline
\end{tabular}

Source: Ho, May-Yei. (2004). Economic Statistics of Major Countries. Taipei: Department of Statistics, Ministry of Economic Affairs. Ho, May-Yei. (2005). Annual the Republic of China. Taipei: Department of Statistics, Ministry of Economic Affairs.

With regional economic blocks taking shape, the Taiwanese government is planning to develop the country into an operations center for the Asia-Pacific region over the next ten years, in an effort to play a key role in the region's economic integration in the twenty-first century. On the business level, it hopes to serve as a stepping stone for local and multinational businesses to invest in and develop Asia-Pacific markets, including Southeast Asia and mainland China. On the macro-economic level, Taiwan plans to become a strong base for developing all kinds of trade and economic relations with Asia-Pacific nations, making it a center of business activities. For example, Taiwan is planning to establish media, financial, manufacturing, telecommunications, sea transportation and air transportation centers based on the following advantages: a geographically-convenient position, a solid manufacturing base, the 
outstanding managerial skills, an abundant supply of high-technology manpower, an attractive domestic market, and a well-developed industrial network of local enterprises. Furthermore, the background of Taiwan's culture is similar to that of mainland China, potentially the largest market in the world.

As of 2004, the total population of Taiwan was 23,132,000 (Ho, 2005). Taipei, located in the north of Taiwan, has the largest population, followed by Kaohsiung, located in the south, followed by Taichung located in the center. Densely populated urban areas have merged around Taipei, forming an interdependent economic and industrial network. For instance, Taoyuan County near Taipei city has the third highest population concentration of Taiwan, after Taipei city and Kaohsiung city. The distribution curve of population indicates a graying population according to age groups. According to 2002 data, the number of people aged 0-14 years comprised about 19.50 percentage of Taiwan population, the group aged 15-64 years comprised about 71.10 percentage, and the group aged 65 years and over comprised about 9.40 percentage (Lin, 2002).

The Taiwan areas compromise 36,000 square kilometers and include Taiwan proper, Orchid Island, Green Island, and the Penghu Islands. Taiwan, an island originally known as Formosa, is located off the eastern coast of China in the Western Pacific, between Japan and Korea to the north and Hong Kong and the Philippines to the south. The Taiwan Strait lies between China and Taiwan, and is approximately 160 kilometers in length. Taiwan is only 377 $\mathrm{km}$ long from the north to the south and $142 \mathrm{~km}$ broad at its widest point. It can be physiographical divided into five major divisions (Lin, 2004): foothills; tablelands; volcanic mountains; the Central Range; and coastal plains and basins.

The Central Range slopes gently to a broad and fertile plain in the west. On the contrary, the mountains descend precipitously to the Pacific in the east. Taiwan's highlands are so extensive so that only approximate one-quarter of the island is arable. Its shore line is fairly straight and therefore good natural harbors are few. Rivers in Taiwan are very short, useful for power generation but not for navigation (Lin, 2004).

Based on the geographic and economic characteristics listed above, the researcher divided Taiwan areas into four ones instead of five, because there is a low concentration of population and business in the central range, which mainly consists of volcanic mountains. The four areas of focus are those in the north, the center, the south, and the east.

The pace of development of rural and urban areas is obviously much different in Taiwan. The population of metropolitan districts continues to grow while that of the rural districts fails to keep a pace. Certain rural towns even saw their populations fall. For example, the population of Wufong village in Taichung County shrunk by almost ten thousand during the period starting from the serious 921 earthquake of 1999 to the end of 2000. Transportation and industrial development in the east and the west of this island is also quite unbalanced (Ho, 2005). Aside from environmental factors, the shortage of managers' knowledge of total quality management (TQM) is the primary barrier to applying TQM in an enterprise (Hansen, et a., 1999; Robbins et al., 2005). Based on the background, this research was focused on the relationship between managers' managerial practices (MP) and the locations of the automotive service businesses.

\section{METHODOLOGY}

The research was conducted by indirect surveying: through a questionnaire investigation. The factors affecting the manager's managerial practice are quite complex (Avolio \& Howell, 1992). There are a lot of studies related to the leader's behaviors and abilities in pass ten years. However, most of them focused on specific behavior and cases. For example, the study of simulative behavior and leadership accountability (Luthas et al., 1985; Podsakoff et al., 1990; Waldman, et al., 1987), the relationships between the leader's planning and his advancement (Howard \& Bray, 1988), the leader's traditional management behavior and the leader's effectiveness (Carroll \& Gillen, 1987; Morse \& Wagner, 1978; Shipper \& Wilson, 1992; Yukl et al., 1990). Only Yukl demonstrated an interest in "Leadership and Behavior" (Yukl, 1989; Yukl, 1994). In addition, due to Taiwan geographic characteristics, the 
researcher is interesting in the locations of automotive service businesses. Therefore, the researcher adopted Yukl's research instrument to investigate the relationship between the managerial practice and locations of automotive service businesses.

Yukl (1994) divided the managerial practice into fourteen different behaviors as follows (pp. 5-25):

- $\quad$ Planning/Organizing - determining long-term objectives and strategies, allocating resources according to priorities, determining how to use personnel and resources efficiently to accomplish a task or project, and determining how to improve coordination, productivity, and effectiveness.

- $\quad$ Problem Solving - identifying work-related problems, analyzing problems in a systematic but timely manner to determine causes and find solutions, and acting decisively to implement solutions and resolve crises.

- Monitoring - gathering information about work activities and external conditions affecting the work, checking on the progress and quality of work, and evaluating the performance of individuals and effectiveness of the organizational unit.

- Networking - socializing informally, developing contacts with people who are a source of information and support, and maintaining contacts through periodic visits, telephone calls, correspondence, and attendance at meetings and social events.

- Informing - disseminating relevant information about decisions, plans, and activities to people who need the information to do their work.

- Clarifying - assigning work, providing direction in how to do the work, and communicating a clear understanding of job responsibilities, task objectives, priorities, deadlines, and performance expectations.

- Motivating/inspiring - using influence techniques that appeal to logic or emotion to generate enthusiasm for the work, commitment to task objectives, and compliance with requests for cooperation, resources, or assistance; also, setting an example of proper behavior.

- Conflict Management/Team-Building - facilitating the constructive resolution of conflict and encouraging cooperation, teamwork, and identification with the organizational unit.

- $\quad$ Supporting - acting friendly and considerate, being patient and helpful and showing sympathy and support when someone is upset or anxious.

- Consulting - checking with people before making changes that affect them, encouraging participation in decision making, and allowing others to influence decisions.

- Recognizing - providing praise and recognition for effective performance significant achievements, and special contributions.

- Developing - providing career counseling and doing things to facilitate someone's skill development and career advancement.

- $\quad$ Rewarding - providing tangible rewards such as pay increase or promotion for effective performance and demonstrated competence.

- $\quad$ Delegating - allowing others to have substantial responsibility and discretion in carrying out work activities and giving them authority to make important decisions.

There are 715 automotive service businesses in total in the Taiwan Areas. 215 businesses are located in the north of Taiwan; 205 are located in the center of Taiwan; 234 are located in the south of Taiwan; only 61 are located in the east of Taiwan. So, census was conducted to investigate the managerial practice and the locations of automotive service businesses. After conducting a questionnaire, the researcher coded the data into the SAS package to run ANOVA (Analysis of Variance) and Scheffe's Test.

\section{DATA ANALYSIS AND RESEARCH FINDINGS}

The research instrument was developed by Yukl et at. (1999) and its theory was based on the theory of reasoned-action (Ajzen \& Madden, 1986). The managerial practice (MP) is constructed by 14 different leadership behaviors. Then, the researcher conducted a census surveying automotive service businesses in Taiwan areas to collect data on the managerial practice. The return rate of the questionnaire was $56.78 \%$ (406 returned/715 populations). Next, 
the data of the respondents was coded into the SAS software package to run the mean of the managerial practice, ANOVA, and Scheffe's Test.

Table 1 show the basic statistics of the managerial practice of automotive service businesses and indicates the MP value is located in the medium range (which means that sometimes the manager of the automotive service business has a good management performance). The scale of the instrument for MP value was divided into five ranges: 1 for "not applicable or do not know," 2 for "never, or not at all," 3 for "seldom, or to a limited extent," 4 for "often, or to considerable extent," and 5 for "nearly always, or to a very great extent."

After running the ANOVA, the data in Table 2 shows the variance analysis of the locations and managerial practices of automotive businesses. It demonstrates the correlation between the locations and managerial practice of automotive service businesses. The $P$ value is less than 0.01 . That means we can further analyze what is the exact correlation between them.

There is at least one pair correlation among northern, central, southern, and eastern areas from Table 1. The results are in Table 3 show the findings of Scheffe's Test of the correlation between locations and managerial practices of automotive service businesses. There are three comparisons $(4-1=-0.39032 ; 4-2=-0.43279 ; 4-3=-0.46687)$ significant at the 0.05 level indicated by “***". That can be interpreted as "The managers who work in the eastern areas have more MP than those who work in the other areas have."

Table 1: Basic Statistic Of The Managerial Practice Of Automotive Service Businesses

\begin{tabular}{ll}
\hline Mean & $\frac{\text { Values }}{2.16}$ \\
Managerial Practice (MP) & 1.97 \\
Planning/Organizing & 2.02 \\
Problem Solving & 2.19 \\
Monitoring & 2.37 \\
Networking & 2.25 \\
Informing & 1.93 \\
Clarifying & 2.07 \\
Motivating/inspiring & 2.08 \\
Conflict Management/Team-Building & 2.13 \\
Supporting & 2.08 \\
Consulting & 2.06 \\
Recognizing & 2.37 \\
Developing & 2.46 \\
Rewarding & 2.25 \\
Delegating & \\
\hline
\end{tabular}

Table 2: Variance Analysis Of The Locations And Managerial Practice Of Automotive Service Businesses

\begin{tabular}{|c|c|c|c|c|c|c|}
\hline Source & DF & $\underline{\text { Sum of Square }}$ & Mean Square & $\underline{\text { F-value }}$ & $\underline{\text { Prob }>F}$ & $\underline{\text { R-square }}$ \\
\hline$\overline{\text { Model }}$ & 3 & 7.11 & 2.37 & $\overline{18.94}$ & $\overline{0.0001} * *$ & 0.1236 \\
\hline Error & 403 & 50.44 & 0.13 & & & \\
\hline $\begin{array}{l}\text { Total } \\
* * p<0.01\end{array}$ & 406 & 57.55 & & & & \\
\hline
\end{tabular}


Table 3: Scheffe's Test Of The Locations And Managerial Practices Of Automotive Service Businesses

\begin{tabular}{|c|c|c|c|c|}
\hline & Simultaneous & & Simultaneous & \\
\hline & Lower & Difference & Lower & \\
\hline Locations & Confidence & Between & Confidence & Significant \\
\hline Comparisons & $\underline{\text { Limit }}$ & Means & $\underline{\text { Limit }}$ & at $5 \%$ Level \\
\hline $3-2$ & -0.10360 & 0.03408 & 0.17176 & \\
\hline $3-1$ & -0.06814 & 0.07654 & 0.22122 & \\
\hline $3-4$ & 0.27592 & 0.46687 & 0.65782 & $* * *$ \\
\hline $2-3$ & -0.17176 & -0.03408 & 0.10360 & \\
\hline $2-1$ & -0.07557 & 0.04246 & 0.16050 & \\
\hline $2-4$ & 0.26114 & 0.43279 & 0.60443 & $* * *$ \\
\hline $1-3$ & -0.22122 & -0.07654 & 0.06814 & \\
\hline $1-2$ & -0.16050 & -0.04246 & 0.07557 & \\
\hline $1-4$ & 0.21782 & 0.39032 & 0.56763 & $* * *$ \\
\hline $4-3$ & -0.65782 & -0.46687 & -0.27592 & $* * *$ \\
\hline $4-2$ & -0.60443 & -0.43279 & -0.26114 & $* * *$ \\
\hline $4-3$ & -0.56763 & -0.39032 & -0.21302 & $* * *$ \\
\hline
\end{tabular}

*** Indicate significance at the 0.05 level with Alpha $=0.05$, confidence $=0.95, \mathrm{df}=403$, and MSE $=0.1252$. (1) Refers to the MP value of the northern automotive service businesses. (2) Refers to the MP value of the central automotive service businesses. (3) Refers to the MP value of the southern automotive service businesses. (4) Refers to the MP value of the eastern automotive service businesses.

\section{CONCLUSIONS}

By considering Taiwan's geography, energy resources, population distribution, future economic growth and so on, Taiwan is well suited to implementing TQM, especially in urban areas. The first step will be to analyze the locations and managerial practices of automotive service businesses.

After running ANOVA and Scheffe's test, there are two main conclusions found in this study. Overall, the value of the managers' managerial practices is 2.16 and fall somewhere between "often" and "sometimes." For the leadership behavior, managers are clearly fulfilling duties (MP value is 1.93). The "planning/organizing" value is 1.97. However, they do not take good care of their employee at all, because the MP values for "rewarding" "networking" and "developing" are very low, 2.46, 2.37 and 2.37, respectively. The other conclusion is that managers working in the eastern part of Taiwan perform better than those working in the other regions in terms of MP.

\section{REFERENCES}

1. Ajzen, I. \& Madden, J.T. (1986). Prediction of goal-directed behavior: Attitudes, intentions, and perceived behavioral control. Journal of Experimental Social Psychology, 22, pp. 453-74.

2. Avolio, G.J. \& Howell, J.M. (1992). The impact of leadership behavior and leader-follower personality matches on satisfaction and unit performance. In K.D. Clark, M.B. Clark, \& D.P. Campbell (Eds.), Impact of Leadership (pp. 225-35). Greensboro, NC: Center for Creative Leadership.

3. Brown, J.S. \& Duguid, P. (2000). Balancing act: how to capture knowledge without killing it. Harvard Business Review, May-June, pp. 73-80. 
4. Carroll, S.J. \& Gillen, D.J. (1987). Are the classical management functions useful in describing managerial work? Academy of Management Review, 12, pp. 38-51.

5. Chao, Yu-Chan. (1999). Effective evaluation of TQM in life technology instruction - an empirical evaluation. Life Technology Instruction, 32(9), pp. 46-49.

6. Davis, E. \& Lea, S.E.G. (1995). Student attitudes to student debt. Journal of Economic Psychology, 16, pp. 663-79.

7. Eddleston, K.A., Kidder, D.L., \& Litzky, B.E. (2002). Who's the boss? Contending with competing expectations from customers and management. Academy of Management Executive, November, pp. 85-95.

8. Ehresman, Terry. (1995). Small business success through TQM: practical methods to improve your organization's performance. Milwaukee, Wis: ASQC Quality Press.

9. Fisher, S.R. \& White, M.A. (2000). Downsizing in a learning organization: are there hidden costs? Academy of Management Review, January, pp. 244-51.

10. Gale, H.F., Wojan, Jr. T.R., \& Olmsted, J.C. (2002). Skills, flexible manufacturing technology, and work organization. Industrial Relations, January, pp. 48-79.

11. Greengard, Samuel. (1997). 25 visionaries who shaped today's workplace. Workforce, January, pp. 50-9.

12. Gupta, A.K., \& Govindaraljan, V. (2002). Cultivating a global mindset. Academy of Management Executive, November, pp. 117-18.

13. Gutek, B.A., Groth, M., \& Cherry, B. (2002). Achieving service through relationships and enhanced encounters. Academy of Management Executive, November, pp. 132-144.

14. Hansen, M.T., Nohria, N., \& Tierney, T. (1999). What is your strategy for managing knowledge? Harvard Business Review, March-April, pp. 106-16.

15. Ho, May-Yei. (2004). Economic Statistics of Major Countries. Taipei: Department of Statistics, Ministry of Economic Affairs.

16. Ho, May-Yei. (2005). Annual the Republic of China. Taipei: Department of Statistics, Ministry of Economic Affairs.

17. Ho, May-Yei (2005). White Book of Small and Medium Business 2005. Taipei: Wu-Nan Culture Plaza.

18. Hof, R.D. \& Hamm, S. (2002). How e-Biz rose, fell, and will rise a new. Business Week, May 13, pp. 64-72.

19. Howard, A. \& Bray, D.W. (1988). Managerial lives in transition: Advancing age and changing times. New York: Guilford Press.

20. Lin, Chia-Lung. (2004). Taiwan Yearbook 2004. Taipei, Taiwan: The Government Information Office.

21. Kesner, R.M. (2002). Running information services as a business: managing IS commitments within the enterprise. Information Strategy, 4, pp15-35.

22. Luthas, F., Rosenkrantz, S.A.\& Hennessey, H.W. (1985). What do successful managers really do? An observation study of managerial activities. Journal of Applied Behavior Science, 21, pp. 255-70.

23. Morse, J.J. \& Wagner, F. R. (1978). Measuring the process of managerial effectiveness. Academy of Management Journal, 21, pp.23-35.

24. Podsakoff, P.M., MacKenzie, S.B., Morrman, R.H., \& Fetter, R. (1990). Transformational leader behaviors and their effects on followers trust in leader, satisfaction, and organizational citizenship behaviors. Leadership Quarterly, 1, pp. 107-42.

25. Pugh, S.D., Dietz, J., Wiley, J.Q., \& Brooks, S.M. (2002). Driving service effectiveness through employee-customer linkages. Academy of Management Executive, November, pp. 73-84.

26. Robbins, Stephen P. \& Coulter, Mary. (2005). Management. Upper Saddle River, NJ: Pearson Prentice Hall.

27. Samson, Danny \& Daft, Richard L. (2003). Management. Southbank, Victoria: Nelson Australia Pty Limited.

28. Shipper, F. \& Wilson, C.L. (1992). The impact of managerial behaviors on group performance, stress, and commitment. In K.E. Clark, M.B. Clark, \& D.P. Campbell (Eds), Impact of Leadership (pp. 119-29). Greensboro, NC: Center for Creative Leadership.

29. Sohal, Amrik. (1997). TQM in Australia: factors critical to success. Caulfield, East, Vic: Faculty of Business and Economics. 
30. Waldman, D.A., Bass, B.M., \& Einstein, W.O. (1987). Effort, performance, and transformational leadership in industrial and military service. Journal of Occupational Psychology, 60, 1-10.

31. Williams, K. \& Johnson, B. (2004). Introducing Management: a Development Guide. (2 ${ }^{\text {nd }}$ ed.). Burlington, MA: Elsevier Butterworth-Heinemann, pp. 48-49.

32. Yukl, Gary. (1999). Short version of managerial practices survey. In Geisler (Editor). Methodology, theory, and knowledge in the managerial and organization sciences: Actions and consequences. Westport, CT: Greenwood Publishing Group, Inc. pp. 261-64.

33. Yukl, G. (1989). Leadership in organizations. 2nd edition. Englewood Cliffs, NJ: Prentice Hall.

34. Yukl, G. (1994). Leadership in organizations. 3rd edition. Englewood Cliffs, NJ: Prentice Hall.

35. Yukl, G., Wall, S., \& Lepsinger, R. (1990). Preliminary report on validation of the managerial practices survey. In K.E. Clark \& M.B. Clark (Eds), Measures of Leadership (pp. 223-38). West Orange, NJ: Leadership Library of America.

\section{NOTES}

